\title{
An Examination of the Tribal Community Dimensions of ICT Users
}

\author{
ANA PINTO DE LIMA \\ Polytechnic Institute of Porto, ISCAP_School of Accounting \\ and Administration of Porto, S. Mamede de Infesta, Portugal \\ CARLOS BRITO \\ School of Economics, University of Porto, Porto, Portugal
}

\begin{abstract}
Today, the Internet and other information and communication technologies allow us to establish global processes of interaction. In this context, we see the proliferation of groups of individuals motivated by common passions, interests, and opinions in which the value of the connection between them is more important than the functionality of objects. Tribes emerge from an allegiance based on the identification of common tastes and passions, which leads consumers to celebrate connections and shared experiences. This study aims to analyze the tribal dimension of groups of individuals who organize themselves into communities based on information and communication technologies. Through a qualitative analysis, two distinct communities were the basis of the study. The research allowed for identification and assessment of the presence or absence of features of tribal groups and to understand the motivations and incentives of the participants.
\end{abstract}

KEYWORDS postmodernism, relationships, emotion, tribes, interaction, consumerism, virtual communities, information and communication technologies

\section{INTRODUCTION}

Contemporary society is fluid and dynamic when it comes to transmission of information. Consumers' predilections and preferences can be freely

Address correspondence to Ana Pinto de Lima, Polytechnic Institute of Porto, ISCAPSchool of Accounting and Administration of Porto, Rua Jaime Lopes Amorim, S. Mamede de Infesta 4465-004, Portugal. E-mail: analima@iscap.ipp.pt 
expressed and shared in places without borders or territorial boundaries. The need that human beings have to interact, share, and create interest groups, leads to the emergence of new ways of acting. The human being interacts with the environment, developing feelings of belonging and affiliation with other individuals.

Markets are increasingly competitive and offer a wide range of products and services designed to meet the needs and desires of each consumer. Therefore, apart from the traditional demographic or psychographic variables, consumers' needs are nowadays further segmented. The emergence of new technologies entails potential diffusion, interaction, and speed in the propagation of information. Cyberspace is the ideal meeting place for untold numbers of consumers to be closer to those who share the same emotions, opinions, and information about a brand, product, or service. Young people have an almost innate ability to make use of new technologies in all areas of their lives.

This study aims to analyze the tribal dimension of groups of individuals who organize themselves in communities based on information and communication technologies. In order to do this, a study was undertaken with two distinct communities: one community based on mobile communication and the other based on online discussion forums. The methodology used was on the use of focus groups as a way of interacting and getting acquainted with the members' performances in a non-intrusive way. The qualitative studies that were used to consult members of both the communities selected were described, as well as the use of convenience samples. It appears that a simple group of consumers sharing a certain type of consumption should not in itself be considered a tribe.

Following this introduction, the article is divided into seven sections. The next section includes a review of the literature, particularly on postmodernism, tribal consumerism, and the impact of the new information and communication technologies. In the section following that, the research questions are established and the model of analysis used as a basis for the empirical study is developed. The next section presents the adopted methodology, followed by an analysis of the results obtained from the two cases. In the next section, results are discussed in an attempt to provide an answer to the research questions. The article ends with a summary of the major contributions, both theoretical and practical, as well as of the limitations encountered and suggestions for future research in this area.

\section{LITERATURE REVIEW}

\section{Tribalism and Postmodernism}

According to Lipovetsky (1983, 1987, 1990), postmodernism is characterized by individualism and the pursuit of total detachment from social obligations. The postmodern individual, free from the restrictions imposed by the limits 
of communities, is restored to his/her "I" and able to become independent. In postmodernism, the conquest of the "I" became inevitable, each individual showing his/her personality, differentiating him/herself from the others. It is, in theory, the right to unlimited freedom-though obviously limited by economic, political, and intellectual contexts. It is the era of the individual who acts in order to highlight his/her existence and individuality. The concept of mobility characterizes the individual's actions, whether socially or in terms of territory. Cova (1997) states that fragmentation of society and consumerism are two of the most visible consequences of this postmodern individualism. What characterizes postmodern life is the process of egocentricity induced mainly by the inevitable development and widespread use of computers in all aspects of daily life. Postmodernism can be seen as a period of severe social disintegration and of extreme individualism.

Postmodern society, unlike modern society (conceived as a set of social groups and professional rankings), resembles a social network of microgroups where individuals establish strong emotional bonds, as well as a common subculture and outlook on life. According to Cova (1997), social status-defined by the author as the stationary position of an individual in a contemporary social class-is progressively affected by the reconfiguration of society. It changes according to the dynamic and flexible positioning of the individual within and among the so-called postmodern tribes. In this line, Auletta (2008) refers to the case of young executives who in their daily life consume products and services according to their social role at work. However, during the weekend they assume a totally different pattern of consumption since they belong to a tribe of surf.

Even being aware that we are facing a stage of social individualism, triggered by the potential of new technologies, there is a release of individual barriers and constraints that results in new ways of social interaction and organization of communities (Goulding, Shankar, and Elliott 2001). As Maffesoli (1996) puts it, we are facing a redefinition and maintenance of social bonds between individuals. In this line of thought, Cova and Cova (2002) suggests that the common denominator of postmodern tribes is the existence of passion and the act of sharing emotions among their members. Maffesoli adds that postmodern tribes are inherently unstable and do not act according to any parameters set by modern society. However, sharing emotions, lifestyles, new moral beliefs, and practices of consumption is common. Members express their commitment symbolically and through rituals. Tribes can be based on the expression and sharing of emotions and passion.

The concept of tribe is of extreme importance for the understanding of the new consumer (Cova and Cova 2002). Tribes concentrate on the establishment of connections and symbolism that carry a particular significance, helping to maintain individuals in groups. They exist due to the involvement of their members and the demonstration of this involvement through symbolism, rituals, and objects or places of praise. It is also important to note 
that postmodern tribes reflect the need to belong not only to one, but to several groups simultaneously. The messages, signs, and symbols are a way of providing connections between members of a particular tribe.

\section{Tribal Consumption}

The value of a product may be functional (material attributes), symbolic (immaterial attributes), or a mixture of both. What seems to matter is the person in his independence and individuality, compared to others. Consumption is seen as a way for individuals to create and communicate their self-identity (Belk 1988; McIntosh and Schmeichel 2004). In other words, the most valued products and services are those that, through their ability to connect people, support social interaction of the communal type.

Postmodernist tribalism requires a redefinition of the value of goods or services. The latter is of great importance, since it must serve both the person as an individual and also contribute to the unification of the group, "among many" and "between two." It is not the producer who sets the connection value of his product; it is the people who use it who will give it some meaning. Moreover, Cova (1997) states that each person can assign different meanings to objects since such meanings are no longer attached and linked to their material functions. These situations, when repeatedly enacted, become rituals created around objects or places, in circumstances of functional and aesthetic use. It is this aura of mystery that usually confers on objects or places a specific identity or meaning. The ecology of human relationships (i.e., the ability to define new rituals of behavioral codes among people) became one of the major marketing themes of postmodernism (Badot 1993).

Again, according to Cova and Cova (2002), the significance of tribal symbols does not exist by itself; it is fabricated within the tribal culture, and is interpreted and negotiated within a specific subculture. The meaning conferred on products and services is related to the collective experiences that establish an opportunity to affirm, evoke, concede, or revise these meanings. Consequently, it is important to find intangible elements that are imperceptible individually, but may be found and interpreted in collective experiences, which occur in a subculture context. As far as Bauman (1992) is concerned, tribes only exist according to the use of symbols as a way of showing loyalty towards the group.

Auletta (2008) recognizes that consumer preferences have evolved in a tribal manner, and that they are well-known and homogenous preferences capable of creating affinity groups sharing the same cultural and social values. Products, services, brands, and purchase behaviors selected by a group are considered of ethnocentric provenance. Each member of the tribe behaves consistently according to the parameters of preferences that reinforce the sense of connection and belonging to the group. The consumption of products and experiences facilitates social relations as well as individual expression in different groups, according to the role they wish to play. 
Auletta (2008) adds that these groups become tribes when their members share a system of values that leads to consumption patterns by which members send signals concerning their membership, singling out the group. Therefore, preferences become an expression of style, from the physical and visible component to a single communication system of symbols described in values, ideology, ethics, desires, and dreams. Tribal members may also express their unique style through fashion (tattoos, body decoration, and hair color), socialization rituals (music, games, and entertainment), and the purchase and use of brands with symbolic value. The ephemeral postmodern tribes have a great need to consolidate and affirm their unity and, indeed, the fact that they are together is due to something that enhances communication and supports a connection: a site, a crest, a ritual of integration or recognition (Maffesoli 1996).

\section{Information and Communication Technologies and Tribalism}

The development and evolution of new information and communication technologies (ICT) provides an almost real contact between people, thus blurring geographical and cultural barriers. ICT promote a wide distribution of messages, as well as a more dynamic interaction between people. It has become immeasurably easier to spread a message, a thought, and receive the corresponding return.

The current technological revolution is causing major changes in society. The electronic tribes are of substantial importance to marketing strategy (Kozinets 1999). The more consumers use online services, the greater the possibility to participate or be a part of an online community. Once a connection and online interaction with other members has been established, the individual is bound to become a frequent user. Communities' technological support systems enable interaction and the proliferation of messages between their members, directing them to specific physical or virtual spaces (Fremuth, Tasch, and Frankle 2003). The implementation of electronic platforms to support communities means that people can communicate about products or services, which provides access to valuable information about the clients, their attitudes and preferences. A mobile community can be defined as an aggregation of individuals who interact around a shared interest, where the contact between them is established and maintained by mobile technologies (Schubert and Hampe 2006).

Mobile communication communities may be regarded as a natural evolution of virtual tribes. They are the result of the combination of virtual communities and an electronic device, such as a mobile phone. Through the creation and generation of services, suppliers create communication spaces. People may interact in these communication areas on a regular and stable basis, maintaining long-term relationships (Fremuth et al. 2003). Communities based on mobile communications are highly motivated by this 
interaction; the brands promoting these communications are the first to feed its dynamism, providing users with hobbies, music downloads, games, ringtones, and music for mobile phone (Fremuth et al. 2003). Members of a virtual community experience a social reality of permanent exchange of experiences and information, novelties, campaigns, offers, product performances, and the story of a brand. And in this way they become real ambassadors for brands (Kozinets 1999).

According to Godin (2008), tribes are the best media channel, as they have the singularity of neither needing rented spaces nor being for sale, like traditional media. Tribes do what they think they ought to do. The great advantage of creating virtual networks derives from the ability to provide connections between consumers (Kozinets 1999). With the blurring of geographical barriers, together with the potential created by access to the virtual world, consumers easily create and share their preferences within a community. It is in virtual communities that consumers alter their consumption patterns, the significance of products, and the value of brands.

\section{CONCEPTUAL MODEL}

The literature review made it clear that despite the existence of research in the ICT field, there is still room for a deeper and integrated understanding of people's reasons for joining such communities and of the way their members interact. In this context, three research questions emerge.

The first issue has to do with the motivations for joining a community. As seen in literature review, researchers (cf. Cova and Cova 2002) suggest that people are likely to join a group when they identify and share common feelings, opinions, and even emotions. However, little is known with regard to communities based on information and communication technologies. Does this specific context affect the major driving factors for joining? In this regard, the first research question is:

RQ1: What are the main reasons for joining an ICT-based community?

Furthermore, as seen before, there are two key aspects to consider with regard to the way tribes evolve: first, an interest, hobby, or passion to share; and second, a specific way of communicating between its members (Godin 2008). Moreover, in the World Wide Web context, Kozinets (1999) states that the Internet allows permanent contact, since technology tends to be accessible and available anywhere at any time. Nonetheless, there is still room for research on the interaction process involving members of a community based on ICT. In this context, the second research question is:

RQ2: How do members of an ICT-based community interact? 
The third research question is more conceptual in nature when compared to the previous ones, since it has to do with the tribal phenomenon itself. In fact, these communities can arise but they may not have the characteristics of tribes as defined in literature review (cf. Cova and Cova 2002; Auletta 2008). In fact, tribes involve a number of idiosyncrasies related to the emotional side of groups of consumers. Thus, the third research question is:

RQ3: Can an ICT-based community be regarded as a tribe?

In order to provide an answer to these research questions, an analysis model was created. It consists of three parts that seek to respond to each research question (Figure 1).

\section{Part I-Reasons for Joining}

The trigger for the interaction between individuals begins with the identification and sharing of a common feeling, opinion, and emotion, leading to information spreading with no physical boundaries (Cova and Cova 2002).

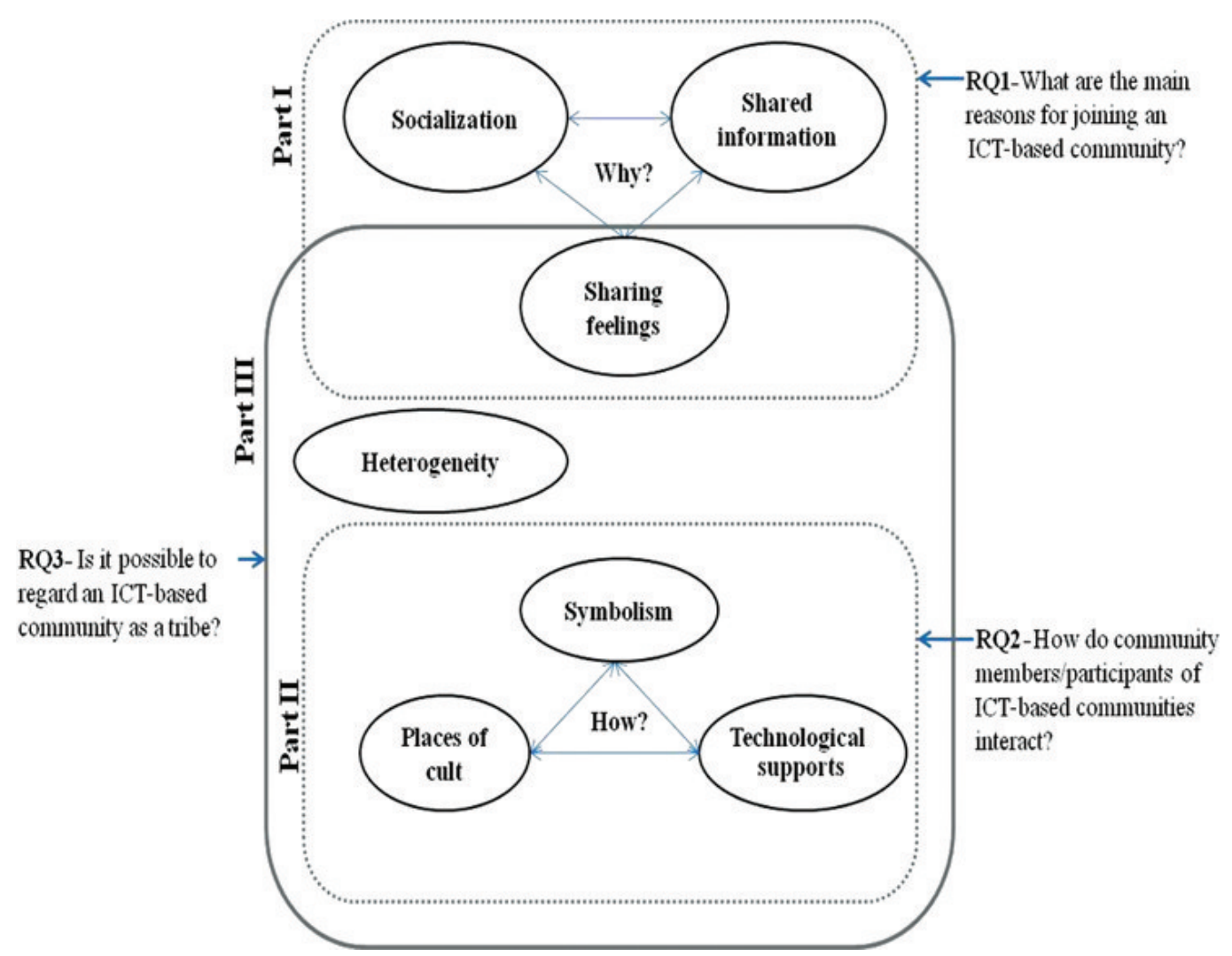

FIGURE 1 Conceptual model (color figure available online). 
There is a link between people based upon this social connection, and consequently a socialization process of those who intend to convey their feelings and emotions. A product or service may play a social supporting role to communities, in the shape of support for co-presence and social affiliations (Cova 1997). The interaction between tribe members comprises a relational component, consisting of a heterogeneous network of people connected by a passion or emotion, capable of collective mobilization.

\section{Part II-Process of Interaction}

The reasons for social bonding are dealt with in the second part of the analysis model: the types of interaction among members. There are two vital aspects to consider with regard to tribes: an interest, hobby, or passion to share and a specific way of communicating between its members (Godin 2008). The Internet allows permanent contact, as long as the technology is accessible and available (Kozinets 1999). The more time consumers spend online, the greater the probability of them participating in or belonging to online communities. It is taken for granted that it is in virtual spaces that members inform other members of new uses for their products/services, offers, and promotional campaigns. Members themselves become responsible for selling, buying, and trading products/services (Kozinets 1999). Through the use of mobile devices and mobile communication services, people can establish a connection anytime, anywhere, to the community, with the benefit of real-time information (Fremuth et al. 2003). Interaction also takes place in physical spaces and members may demonstrate their affiliation through symbols, rituals, and objects/places of cult. Social encounters and rituals may be supported by a unique symbolism: the use of specific clothing when attending a ritual, cult objects, images or words, idols, and icons (Cova and Cova 2002).

\section{Part III-The Tribal Phenomenon}

Tribes comprise heterogeneous groups of people brought together by a common passion or the sharing of feelings. The involvement that motivates the communion between their members can be demonstrated by physical symbols or signs in places of cult. Tribe members do not impose limits on accepting people of different ages. Joining a tribe does not appear to be discriminatory. Tribes must prosper and be able to add something special and meaningful to its members. Therefore, there must be one or more ways for members to communicate, enabling them to spread their emotions and information as fast as possible. Messages are aimed at not only a single member but to many. Tribe members are enthusiastic and may well become true ambassadors of brands, spontaneously promoting products and services in a credible way. The consumerism habits of tribes are considered as almost 
sacred, which reveals the connection between members and leads to the sharing of consuming experiences.

\section{METHODOLOGY}

\section{Methodological Approach}

The methodology used in this study is qualitative, since it concerns the analysis of the emotional and motivational sides of individuals. According to Miles and Huberman (1994), qualitative research methods involve the collection, organization, and interpretation of textual material resulting from conversations and/or observation. It is used in the exploration of meanings of social phenomena in their natural context. A qualitative design is appropriate to explore and understand how and why processes occur and provides deep insight because it is flexible, small-scale, and exploratory (De Ruyter and Scholl 1998). A widely used method is group interviews of members of focus groups. As far as Morgan (1997) is concerned, the focus group is a qualitative technique concentrated on the discussion of a particular subject with a group of people, focusing on the observation and recording of the subjects' experiences and reactions. One of the limitations of this technique is that it can be regarded as being somewhat intrusive and/or inhibiting and the interpretation of the data is often also too complex. For this project, a group of people were chosen who belong to communities of mobile technology users and also a group of members of online discussion forums.

\section{Data Collection}

The study was presented to higher education students of Economics and Management, as young representative members of the chosen case-study communities and also due to the authors' proximity to the study group. After the identification of the participants who fulfilled the intended requirements (age and participation in the communities concerned), they were invited to attend on the dates chosen for the collection of data. All interviews were recorded in audio (a total of 3 hours), with the permission of the participants, as there was the ethical concern to inform them of the procedures followed and their objectives, as well as of the importance of their contribution.

Data collection was based on two focus groups. The first included 10 participants involved in communities of mobile communications. The second focus group was made up of seven active participants in at least one online discussion forum. Both sessions were recorded in audio (in a total of 3 hours), with the permission of the participants. There was the ethical concern to inform them in the beginning of the session about the agenda to be followed, as well as about the importance of their contribution. 


\section{Data Analysis}

After collecting data from the two focus groups, all the information was carefully listened to at different times of evaluation. First, the most important information from the mobile communication community was registered. Afterwards, it was compared to the analysis model, in the three sections used as the authors' working instrument. Subsequently, the information obtained from the second focus group, the online discussion forums, was registered and continuously compared to the variables present in the analysis model.

\section{RESULTS}

\section{Mobile Communication Communities}

Mobile communication communities (MCC) are strongly supported by people who recognize within them a means of communication based on technological support that provides innovative solutions regarding access and connectivity. Young people are one of the segments with greater propensity to adopt new mobile telecommunications products and services.

In Portugal, there are three mobile communication communities supported and managed by leading telecom operators: Vodafone's Yorn Extravaganza, Optimus' Tag, and TMN's Moche. In this study, the first analysis case relates to these mobile communication communities that are part of the services provided by mobile operators. Table 1 summarizes the data obtained by crossing them with the constructs of the conceptual model.

TABLE 1 Mobile Communication Communities: Analysis Summary

\begin{tabular}{cl}
\hline Mobile communication communities \\
\hline $\begin{array}{c}\text { Motivation } \\
\text { (Why?) }\end{array}$ & - Friends suggest it or are already members of a community. \\
& - Cheap communications with counterparts when using the services provided \\
& by a certain operator. \\
- To keep a restricted group of friends in permanent contact by using the & services provided by a certain operator. \\
Interaction & - Mobile devices (voice and texting). \\
(How? $)$ & Meetings are casual and do not act as celebrations of connections between \\
& - Thembers. \\
Tribal & - Existence of requirements for the admission of new members. \\
dimension & - Interaction based on rationality and a community with no ability to profit from \\
& shared information. \\
& - Only accept new members of the same age who are already friends/ \\
& acquaintances and/or acquainted to another member. \\
- The shared information is simple, trivial and does not concern opinion, & passion or feelings towards something. The group does not prosper.
\end{tabular}


A tribal dimension involves a set of interrelated concepts that reveal the presence of tribal features in communities, according to the analysis model. There are few tribal characteristics to be found in the MCC members used as subjects. Regarding the heterogeneity in acceptance of members, it appears that there is no place for integrating new members in the community, if there is no degree of acquaintance, friendship, or kinship with others. The acceptance of members is not based on experience, the value of connection, the ability to become a relevant member, or the emotion of having something in common to share. Acceptance is based on prior acquaintance and members do not accept people of different age groups. There is, in fact, a common and restricted means of communication (mobile devices); nevertheless, the value of their connection is not based on a common interest, preference, or passion, but on casual conversations, common among people in the same age group, with no intention of being valuable to the community.

Using personal devices as a means of private communication leads to the creation of a kind of private community with full control of its owner. Symbols are null, as members do not wear/use any type of symbol or prop that identifies them as belonging to a community. Meetings are based on pre-arranged and/or sporadic gatherings in places of leisure, entertainment, and schools. Some individuals admitted to belonging to more than one mobile communication network, as they want to benefit from the same communication advantages with friends who use different operators.

Members are aware that they do not need to acquire further communication services from mobile operators, nor do they feel pressured or motivated to do so, implying a clear understanding that its use is limited to what is essential to keep them in touch. The degree of involvement is largely limited to the relationship and interests shared by the community. The conversations are based on friendship and are not useful, or valuable to members. After this summary of the data collected from the focus group of mobile communities, the next step is the analysis of the data collected from the online discussion forum focus group.

\section{Online Discussion Forums}

Online discussion forums are virtual meeting points for people who share a similar interest and establish contact with other people by posting messages online. In these virtual meeting spaces it is usual to witness conversations about products and brands, which are often fundamental for establishing a connection with others, without being invasive. Indeed, many of the subjects discussed reveal the presence of people who seek further information in order to decide on a purchase; others are mere opinions concerning preferences or current events. Table 2 summarizes the data obtained by crossing them with the constructs of the conceptual model. 
TABLE 2 Online Discussion Forums: Analysis Summary

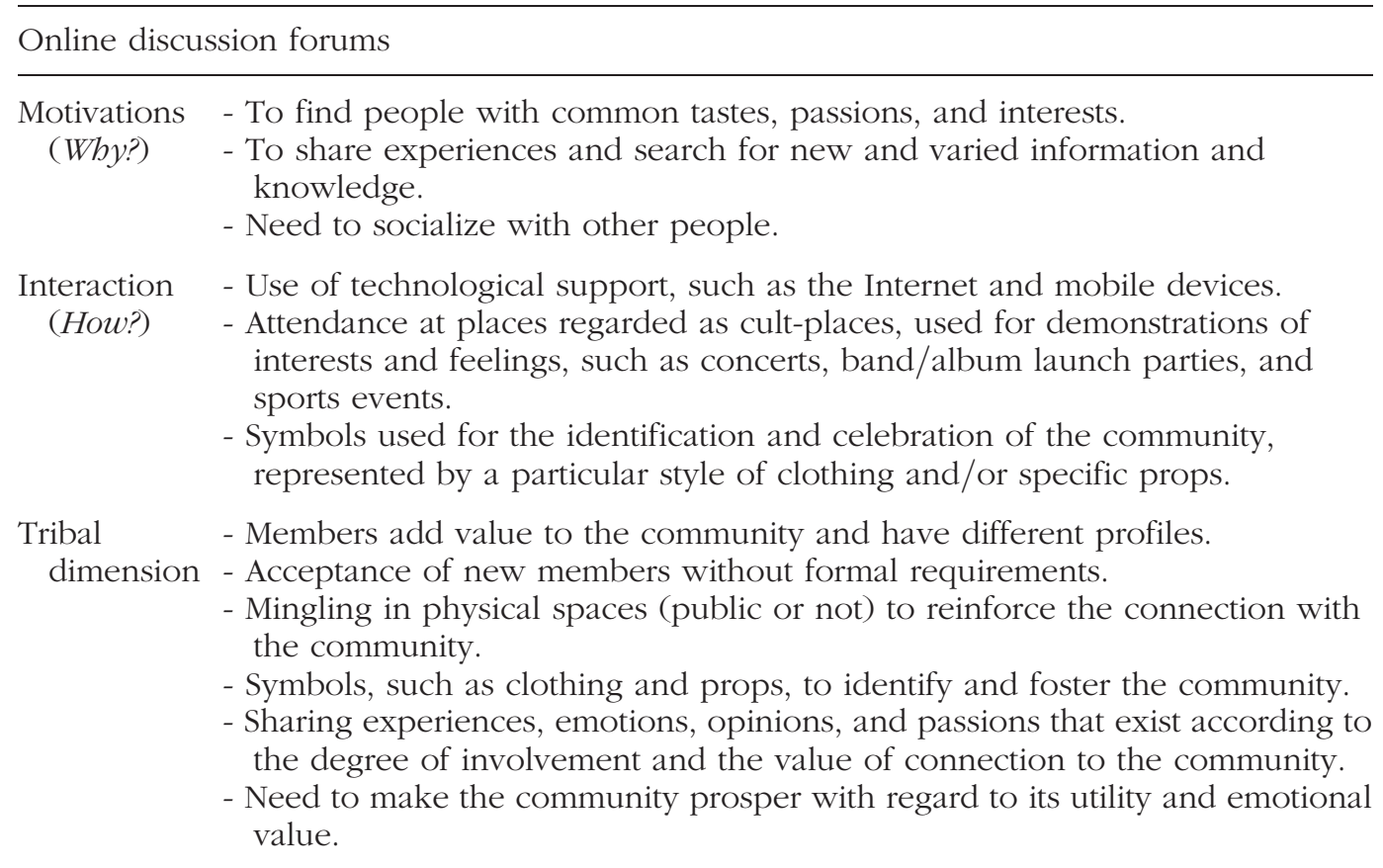

The acceptance of people in the forum, with the purpose of exchanging points of view, is not based on demographic or geographic criteria, but on the harmony and compatibility of the opinions conveyed, as well as on the consistency of members' participation in the forum. And thus, the way participants express their opinions and experiences becomes a major condition for interacting. The community may accept heterogeneous and geographically distant members, since importance is given to the contribution that each person brings to the forum and the credibility of the experiences shared, adding value to the forum.

Participants are driven by the value of opinions and their credibility, as well as by the history of messages from members. This group appears to be heterogeneous regarding the composition of members. Thus, as long as a user has a passion, opinion, or experience to share, he/she is able to interact without any restriction or limitation as to age, nationality, or lifestyle. The stronger the compatibility of interests, the greater the involvement of people when interacting with the community. Moreover, participants choose with whom they want to exchange emotions, opinions, and interests concerning a certain subject, using a specific means of communication-the Internetaccessible and available at all times. The existence of a virtual meeting place allows interaction to become public to all members interested in the theme of the forums.

New people join spontaneously, with no previously established rules, as long as they have something to add to the community. Members may (and do) influence, spread information, and make other members evolve. When 
involved in the same musical or sports events, members share symbols that are specific to each theme, from clothing to a general look, from head to toe. It was also acknowledged by those interviewed that there exist rituals and the use of common expressions, both before and during encounters in places referred to as being part of the "cult" for a specific theme. These events, therefore, reinforce the value of the connection and involvement among members, and foster the sharing of emotions among community members.

\section{DISCUSSION}

Appendix tables A1, A2, and A3 summarize the answers to the three research questions. These answers reveal a group of people with certain characteristics but these groups cannot always be regarded as having tribal dimension. According to Cova and Cova (2002), to join a tribe people have to share similar interests. However, this is not enough inasmuch as the members must be linked by emotional bonds. In this study, evidence was found that online forums were based on shared passions, such as listening to music or playing games. It is, therefore, necessary to understand the real motivations that drive an individual to join his/her peers with similar values. It is evident that having a common means of communication is not enough. The existence of unity, identification with a community/brand and its members, as well as sharing passions, emotions, and experiences is essential.

According to Kozinets (1999), tribes are more than just "communities of interests," since the emotional connection is critical. It was found that online consumers are more active, participatory, resistant, activist, socially engaged than members of mobile communications communities. The main purpose of online forums is not to control information, but to use it wisely in order to build solid and lasting relationships. Here, emotions make all the difference in increasing the value of the connection (that goes beyond any kind of rationality), which can be demonstrated by the use of symbols, ways of living, and the participation in cult events.

The new technologies have eliminated boundaries, uniting countless people through a common feeling and emotion with a simple click. Kozinets (1999) states that as more consumers gravitate online, the more likely they are to be involved in online forums. Once initiated the connection and interaction with other members online is possible that the individual becomes a regular member. It is important to note that tribes have a dynamic and ephemeral character; the union shared by its members may be volatile, increasing the value and the intensity of this connection due to the fact that these communities are often short-lived. To Cova and Cova (2002), the members of a tribe are free to belong to more than one tribe and the tribes have an ephemeral and unstable nature. This means that the intensity of the relationship is stronger while the tribe remains united and dynamic. 
The connection between MCC members comes almost entirely from pre-existing relationships between members, while the strength of the connection between members of online forums is much more intense, as it is rooted in common values, opinions, and passions. Therefore, after the cross-sectional analysis of the variables underlying the model, it is possible to state that MCC do not have a tribal dimension.

Online discussion forums may be regarded as tribal communities. They share emotions, experiences, opinions, show heterogeneity in their relations, and celebrate the value of their connection with symbolism. The motivation for getting involved in the community, as well as the ways of interacting and participating, show that communities based on online discussion forums are more compatible with the proposed analysis model, as they have greater propensity to act as a tribe. Therefore, the second case study proves to be the most compatible with the proposed analysis model, corroborating and extending the current literature and conceptualization.

\section{CONCLUSION}

This study advances the understanding of tribal dimensions among groups with interests and common passions. To regard as tribes groups that do not have tribal characteristics can lead to wrong marketing messages. It is therefore important for brands to understand whether or not their target market includes tribes that spread information and emotions about the brand, product/service, adding value to the market. It is important to recognize the potential of a member of a tribe and his/her leadership characteristics regarding the other members. Awareness of the underlying reasons for an association and how interaction takes place within it is a powerful source of information for companies intending to create emotional and affective relationships with consumers.

\section{Theoretical Contributions}

In this context, the main theoretical contributions of the study are:

- Fake tribalism. This study confirmed that simply because a group exists and is based on communication technology does not mean that it has all the necessary characteristics to be considered a tribe. These groups tend to wrongly see themselves as tribes, although they often comprise groups of consumers who do not share the same feelings, emotions, and consumerism experiences. They incorrectly take simple technological instruments as symbols, although the consuming habits of these groups (pseudo-tribes) are not in any way sacred or representative of a celebration of the connection between their members. These groups may 
be united by functionality/utility rather than by emotions and shared information and experiences. The mere fact that people socialize in a group and have specific ways of communicating with each other is not enough for a group to assume as a tribal dimension.

- "Right of admission reserved." The study also revealed that the value of the connection involving members can overcome geographic and demographic barriers, based on a shared passion and on the significance and influence of the opinions exchanged. However, it is noticeable that ideological barriers, which are to some extent based on prejudice, may exist in members of the tribes. Thus, existing members accept potential new members based on the value of their emotional contribution to the tribe; however, there are coexisting feelings of choice and selection of members due matters concerning ideologies or importance. It is important to note that, although admission is free, some members may reveal prejudice when connecting emotionally with new members who adopt a controversial or openly ideological attitude.

\section{Managerial Contributions}

The main practical contributions of the study are:

- Exploration of emotions, passions, feelings. Tribes are connected by passion, devotion to something, and as such are of great importance for brands to be able to understand the feelings to which the consumers are more sensitive and how they value shared messages and experiences. It is also important to understand to which stimuli those consumers are more receptive and how this influences other members.

- Creation of and encouragement for the use of media interaction. In order to be able to share experiences and emotions, tribe members must have easily accessible means of communication. It is necessary to encourage the use of media technology as a meeting point and for interaction.

- Creation of an identity. The emotional connection between tribe members may be reflected in affection for a brand, product, or service. Those managers aware of this phenomenon may contribute to the creation of an identity, as well as the identification of the tribe with a brand, promoting the widespread use of symbols and celebratory events in places of entertainment, such as music festivals, meetings, events to launch or test certain products, among others.

- Obtaining feedback concerning the market and consumer experiences. Proximity to tribes allows managers to truly understand members' motivations and consumption desires. The information gathered by the interactions observed is more valuable and genuine as it is provided in easy-going, relaxed environments and by people who are emotionally connected to the brand, product, or service, allowing businesses to customize their offer. 


\section{Limitations and Suggestions for Future Research}

This study has some limitations that are presented below. First, an intrinsic limitation relates to the fact that the researcher led all the process of qualitative methodology. Then, using qualitative methodology has obvious limitations as it generalizes the results of a study that was confined only to a particular sample. In this particular case, the study was limited to two focus groups of students, a convenient sample based on the availability of participants. The fact that it regards a specific case study based on empirical methodology limits the generalization of the collected data. Regarding suggestions for future research, the study could be extended to other tribal-type contexts by analyzing a variety of emerging cases as well as the possibility of a group, unified by the rationality of a union with material counterparts, reaching a state of shared emotion.

In sum, this is not a project that has come to an end; it is the beginning of a study that has proven to be successful and which covers a topic that in the future may be the basis for further research with relevant considerations for companies intending to get to know the tribal characteristics of their consumers and how best to deal with them.

\section{REFERENCES}

Auletta, N. 2008. Un mundo de tribus: Los jóvenes consumidores. In Revista debates. Caracas: IESA.

Badot, O., A. Bucci, and B. Cova. 1993. Societing: Managerial response to European aestheticization. European Management Journal Special Issue EAP 20th Anniversary, 48-56.

Bauman, Z. 1992. Intimations of postmodernity. New York: Routledge.

Belk, R. 1988. Possessions and the extended self. Journal of Consumer Research 15 (2): 139-168.

Cova, B. 1997. Community and consumption: Towards a definition of the linking value of products or services. European Journal of Marketing 31 (3/4): 297-316.

Cova, B., and V. Cova. 2002. Tribal marketing: The tribalisation of society and its impact on the conduct of marketing. European Journal of Marketing 36 (5/6): 595-620.

De Ruyter, K., and Scholl, N. 1998. Positioning qualitative market research: Reflections from theory and practice. Qualitative Market Research 1:7-14.

Fremuth, N., A. Tasch, and M. Frankle. 2003. Mobile communities-New business opportunities for mobile network operators? In Proceedings of the International Workshop on Mobile Multimedia Communications, October 5-8, Munich, Germany.

Godin, S. 2008. Tribes: We need you to lead us. New York: Penguin.

Goulding, C., A. Shankar, and R. Elliott. 2001. Dance clubs, rave and the consumer experience: An exploratory study of a cultural phenomenon. Proceedings of the European Association for Consumer Research Annual Conference, Berlin, Germany.

Kozinets, R. 1999. E-tribalised marketing? The strategic implications of virtual communities of consumption. European Management Journal 17:252-264.

Lipovetsky, G. 1983. L'ère du vide: Essais sur l'individualisme contemporain. Paris: Gallimard. 
Lipovetsky, G. 1987. L'empire de l'éphémère: La mode et son destin dans les sociétés modernes. Paris: Gallimard.

Lipovetsky, G. 1990. Virage culturel, persistance du moi. Le debat 60 (May/August): 264-269.

Maffesoli, M. 1996. The time of the tribes. London: Sage.

McIntosh, W., and B. Schmeichel. 2004. Collectors and collecting: A social psychological perspective. Leisure Sciences 26:85-97.

Miles, M., and A. Huberman. 1994. Qualitative data analysis. 2nd ed. Thousand Oaks, CA: Sage.

Morgan, D. 1997. Focus group as qualitative research. 2nd ed. London: Sage.

Schubert, P., and J. Hampe. 2006. Mobile communities: How viable are their business models? An exemplary investigation of the leisure industry. Electronic Commerce Research 6 (1): 103-121.

\section{APPENDIX}

TABLE A1 Summary of Conclusions Related to the First Research Question

RQ1: What are the main reasons for joining a community based on ICT?

Objective Investigate the motivations and incentives for the presence of members of a community based on ICT.

Results

Socialization It appears that the mobile community (CMC) study is based on a concept of a group of friends and family that interact according to rational cost/benefit. The union of the group through the features of technological support is appreciated in the context of advantages offered by mobile operators. These members plan to maintain permanent contact with the small group with a view to beneficial use. In turn, members of online discussion forums join the community with the intention of meeting people outside their circle of friends and family. They have the aim to find people with similar emotion, passion, and experiences, and online forums can provide it. They have the need to socialize with others (known or not) in one accessible place.

Shared In the CMC the exchange of information is very limited, since they share only information the events of the day to day trivialities shared with the small group and do not contribute to the community to thrive and add significant value to its members; by contrast, moreover, it has become apparent in the online forums. The forum members interact online in order to add value and prosper in any form or area of interest. There is a sharing of experiences and information about products/services, in which some members are seen with the authority to recommend certain uses and performance of products/ brands. The information shared is sometimes enlightening for members to carry out consumer decisions.

Sharing The CMC members share friendship and companionship, but do not reveal the feelings union by emotion or passion for something. However, in the online forums the motivations are cognitive, with particular emphasis on the sharing of experiences, tastes, opinions, and recommendations with the community. Some thematics fit common emotions and passions that identify and link people around these feelings. 
TABLE A2 Summary of Conclusions Related to the Second Research Question

\begin{tabular}{|c|c|}
\hline Objective & $\begin{array}{l}\text { To analyze the member's interaction, especially the technological supports } \\
\text { used, the symbolism, and value of the link. }\end{array}$ \\
\hline \multicolumn{2}{|l|}{ Results } \\
\hline $\begin{array}{l}\text { Technological } \\
\text { supports }\end{array}$ & $\begin{array}{l}\text { The most common technological supports used by CMC members are the } \\
\text { mobile cell phones for voice calls and sending text messages and images. } \\
\text { The forums' members are supported by Internet communication and } \\
\text { sometimes, the mobile communications. }\end{array}$ \\
\hline $\begin{array}{l}\text { Places } \\
\text { of cult }\end{array}$ & $\begin{array}{l}\text { The CMC members only have casual encounters unrepresentative of } \\
\text { demonstrations of the value of the link as they represent sporadic meetings } \\
\text { with the friends. } \\
\text { Though forums' members have a physical presence in space for socializing } \\
\text { and expression of interests and feelings, for example, participation in } \\
\text { concerts, launch parties for bands, and sporting events. In this sense, there is } \\
\text { a celebration of passion. }\end{array}$ \\
\hline Symbolism & $\begin{array}{l}\text { In CMC there is symbolism between the members. } \\
\text { In online forums there is some symbolism that is used for the identification } \\
\text { and celebration of community, represented by the clothing and some props. } \\
\text { The symbolism is more appreciated in forums whose subject is music or } \\
\text { sports (especially football). }\end{array}$ \\
\hline
\end{tabular}

TABLE A3 Summary of Conclusions Related to the Third Research Question RQ3: Is it possible to regard an ICT-based community as a tribe?

\begin{tabular}{|c|c|}
\hline Objective & $\begin{array}{l}\text { To observe if the key features of a tribe are present in the communities } \\
\text { analyzed in order to measure to what extent they exhibit a tribal } \\
\text { dimension. }\end{array}$ \\
\hline \multicolumn{2}{|l|}{ Results } \\
\hline & $\begin{array}{l}\text { According to the key features that were considered to assess the extent of } \\
\text { tribal dimension, the following results analysis is defined: }\end{array}$ \\
\hline $\begin{array}{l}\text { Sharing } \\
\text { feelings/ } \\
\text { heterogeneity }\end{array}$ & $\begin{array}{l}\text { The CMC had no interactions established by the share of feelings to motivate } \\
\text { union members; they denote rational reasons for the presence in the } \\
\text { group. Members present selection criteria on the entry of new members in } \\
\text { the community and, as such, violate one of the key concepts of tribalism: } \\
\text { the elimination of geographic or demographic and psychographic nature. }\end{array}$ \\
\hline $\begin{array}{l}\text { Technological } \\
\text { supports }\end{array}$ & $\begin{array}{l}\text { The CMC analyzed only used the communication to keep in touch. They do } \\
\text { not aspire to prosper or contribute to the value of their personal } \\
\text { experiences or consumption. There is a lack of physical locations and } \\
\text { symbols that express the value of connection. }\end{array}$ \\
\hline $\begin{array}{l}\text { Places of } \\
\text { cult/ } \\
\text { symbolism }\end{array}$ & $\begin{array}{l}\text { The forums' members have a constant sharing of opinions, emotions, } \\
\text { experiences, and information that add value to the community. It appears } \\
\text { that the interaction occurs with anyone who has an opinion, shares a } \\
\text { passion or feeling about something, so that heterogeneity is a strong } \\
\text { concept in the community. They have a way of communicating between } \\
\text { members through the technological supports but either by physical } \\
\text { presence in places of cult to symbolize the value of the link. The members } \\
\text { use certain symbols in their interactions as a form of identity and } \\
\text { identification. }\end{array}$ \\
\hline
\end{tabular}

